\title{
Preoperative education with image illustrations enhances the effect of tetracaine mucilage in alleviating postoperative catheter-related bladder discomfort: a prospective, randomized, controlled study
}

Li Zhou $^{1+}$, Le Zhou ${ }^{2+}$, Leilei Tian', Daojun Zhu', Ziwen Chen', Chang Zheng ${ }^{1}$, Ting Zhou', Xianzheng Zeng ${ }^{1}$, Xiaojuan Jiang ${ }^{1}$, Chunling Jiang ${ }^{1 *}$ (i) and Lulong $\mathrm{Bo}^{3^{*}}$

\begin{abstract}
Background: Catheter-related bladder discomfort (CRBD), secondary to catheterization of urinary bladder is distressing. The aim of this study was to assess the efficacy of preoperative education on CRBD with image illustration for alleviating CRBD.
\end{abstract}

Methods: Sixty adult male patients, undergoing elective colonal and rectal surgery, were randomized to receive tetracaine mucilage instilled into the urethra and applied to the catheter (tetracain group), or receive tetracaine mucilage in combination with image illustration on CRBD (image group) before urethral catheterization. The incidence and severity of CRBD were assessed at $0.5,1,2$, and $6 \mathrm{~h}$ after patients' extubation. The severity of postoperative pain, incidence of postoperative agitation and other adverse events were also recorded.

Results: Patients in image group reported remarkably less CRBD than those in tetracaine group at 0.5,1, 2 and $6 \mathrm{~h}$ after extubation (20, 20, 6.7 and $6.7 \%$ v.s. $60,73.3,53.3$ and $53.3 \%$, respectively, $P<0.01)$. Severe CRBD was not reported in either group. However, the incidence of moderate CRBD was significantly lower in image group, with $6.7 \%$ at $1 \mathrm{~h}$ and thereafter none occurred, compared to $6.7 \%$ at $0.5 \mathrm{~h}$, and increasing to $20 \%$ at $1 \mathrm{~h}, 2 \mathrm{~h}$ and $6 \mathrm{~h}$ in tetracaine group, respectively. Moreover, patients in image group suffered less moderate to severe postoperative pain than that of tetracaine group (13.3\% v.s. $40.0 \%$ at $1 \mathrm{~h}, P=0.039,33.3 \%$ v.s. $60 \%$ at $2 \mathrm{~h}$ and $6 \mathrm{~h}, P=0.038)$.

Conclusions: Preoperative education on uretheral catheterization via image illustrations could enhance the effect of tetracaine mucilage in reducing both the incidence and severity of CRBD.

Trial registration: The trial was registered at www, clinicaltrials.gov with registration number NCT03199105 (retrospectively registered). Date of trial registration which is "June 26, 2017".

Keywords: Catheter-related bladder discomfort, Urethral catheterization, Preoperative education, Image illustration, Tetracaine

\footnotetext{
* Correspondence: jiang_chunling@yahoo.com; bartbo@smmu.edu.cn

${ }^{\dagger} \mathrm{Li}$ Zhou and Le Zhou contributed equally to this work.

'Department of Anaesthesiology and Translational Neuroscience Center,

West China Hospital, Sichuan University, Chengdu 610041, Sichuan, China

${ }^{3}$ Faculty of Anaesthesiology, Changhai Hospital, Naval Medical University,

Shanghai 200433, China

Full list of author information is available at the end of the article
}

(c) The Author(s). 2018 Open Access This article is distributed under the terms of the Creative Commons Attribution 4.0 International License (http://creativecommons.org/licenses/by/4.0/), which permits unrestricted use, distribution, and reproduction in any medium, provided you give appropriate credit to the original author(s) and the source, provide a link to the Creative Commons license, and indicate if changes were made. The Creative Commons Public Domain Dedication waiver (http://creativecommons.org/publicdomain/zero/1.0/) applies to the data made available in this article, unless otherwise stated. 


\section{Background}

Catheter-related bladder discomfort (CRBD), characterized by a burning sensation with an urge to void or discomfort in the suprapubic area [1, 2], are extremely distressing, and are frequently associated with emergence agitation [3, 4], exacerbated postoperative pain and other postoperative complications $[3,5]$. Systemic administration of tramadol, tolterodine, oxybutynin, or gabapentin, et al., were reported effective in reducing CRBD [2, 3, 6-10]. Nevertheless, side effects such as postoperative nausea, vomiting, sedation, and dry mouth, et al., usually occur $[2,6,7,11]$. Lubricants containing local anesthetic such as lidocaine or tetracaine $[12,13]$, instilled into the urethra or applied on the catheter, are increasingly used in urethral catheterization to minimize urethral trauma and CRBD to certain extent [1]. However, no effective treatment for CRBD without adverse effects has been established yet.

On the other hand, growing evidence shows that preoperative anxiety contributes greatly to postoperative pain and discomfort [14]. Studies in patients have demonstrated that specific education, via verbal instruction and/or in conjunction with pamphlet, photo file or illustration, given prior to the surgery [15] can help patients obtain better pain relief $[16,17]$, alleviate anxiety and discomfort $[18,19]$. However, for patients with low literacy skills, preoperative education via pictures and illustrations are especially useful [20]. These findings shed light on the possibility that specific preoperative education on uretheral catheterization may decrease postoperative CRBD.

Giving specific information via verbal instruction in conjunction with image illustration to patients requiring urethral catheterization, our aim is to determine whether preoperative education on uretheral catheterization enhances the effect of local anesthetic tetracaine mucilage in alleviating postoperative CRBD.

\section{Methods}

After obtaining Ethics approval (Ethical Committee $\mathrm{N}^{\circ}$ 2014-159) from the Ethical Committee of West China Hospital, Chengdu, China on 23 December 2014, we conducted this prospective, randomized, controlled study in West China hospital according to the principles expressed in the Declaration of Helsinki. From July 2017 to May 2018, Adult, male patients (18-75 yr), with an ASA physical status I or II, who were to undergo elective colonal and rectal surgery with surgical duration of at least $2 \mathrm{~h}$, requiring catheterization of the urinary bladder and were able to understand the rationale of the study and provided with informed consent, were consecutively included. Patients with a bladder outflow obstruction, e.g., continuous feeling of a full bladder, frequent urination, pain during urination (dysuria), problems starting urination (urinary hesitancy), slow, uneven urine flow, at times being unable to urinate, et al., or a medical history of bladder outflow obstruction, which is diagnosed by urologist, overactive bladder (frequency $>3$ times in the night or $>8$ times in $24 \mathrm{~h})$, neurogenic bladder, end-stage renal disease (urine output $<500 \mathrm{~mL} / 24 \mathrm{~h}$ ), coagulopathy, morbid obesity, disturbance of central nervous system, chronic pain, chronic medicine usage (e.g., opioids, anticholinergic or NSAID), and any psychiatric disease were excluded from the study.

Patients enrolled were randomized to either group using the computer-generated random numbers. A sealed envelope containing a random number was opened during the preoperative interview (one day prior to surgery) by a nurse. Patients in tetracaine group received 1\% tetracaine mucilage (Xi'an Lijun Pharmaceutical Co., Ltd., Xi'an, China), instilled into the urethra and applied to the catheter before urethral catheterization after the anesthesia induction. The patients in image group were educated on the whole process from catheterization to emergence and the symptoms of CRBD by image illustration (Fig. 1) during the preoperative interview. Then the urethral catheter was prepared and placed in the same way as in tetracain group.

All participants received a peripheral intravenous line using a 16-gauge catheter, and routine anesthesia monitoring including electrocardiography, heart rate, noninvasive blood pressure, and pulse oximetry continuously after arriving at operation room. Anesthesia was induced with midazolam $0.03 \mathrm{mg} \cdot \mathrm{kg}^{-1}$, sufentanil $0.4 \mu \mathrm{g} \cdot \mathrm{kg}^{-1}$, cis-atracurium $0.2 \mathrm{mg} \cdot \mathrm{kg}^{-1}$, and propofol $2 \mathrm{mg} \cdot \mathrm{kg}^{-1}$. Anesthesia was maintained with inhalation of $1.5-2.5 \%$ vol of sevoflurane and intermittent sulfentanil and cis-atracurium as required. Urinary catheterization was performed with a 16 Fr Foley catheter and the balloon was inflated with $10 \mathrm{ml}$ of $0.9 \% \mathrm{NaCl}$, then fixed with an adhesive tape without any traction and allowed the urine to drain freely into a bag. Last dose of sulfentanil was administered $30 \mathrm{~min}$ before completion of surgery. After the surgery, muscle relaxation was antagonized with neostigmine $0.02 \mathrm{mg} \cdot \mathrm{kg}^{-1}$ and glycopyrrolate $0.01 \mathrm{mg} \cdot \mathrm{kg}^{-1}$. Patients were then extubated and transferred to the postanesthesia care unit (PACU). If patients complained about pain in the PACU, they were enquired to confirm whether it was incision pain or discomfort related to urinary bladder. Sufentanil $5 \mu \mathrm{g}$ i.v.was given to patients with VAS scores $\geq 4$ after confirmation of postoperative pain but not for CRBD.

The primary outcome of the study is the incidence of CRBD. The secondary outcomes include the severity of CRBD, the incidence and severity of postoperative pain, the incidence of postoperative agitation, and adverse events, such as respiratory depression $\left(\mathrm{SpO}_{2}<90 \%\right)$, 


\section{Instruction for Urethral Catheterization}
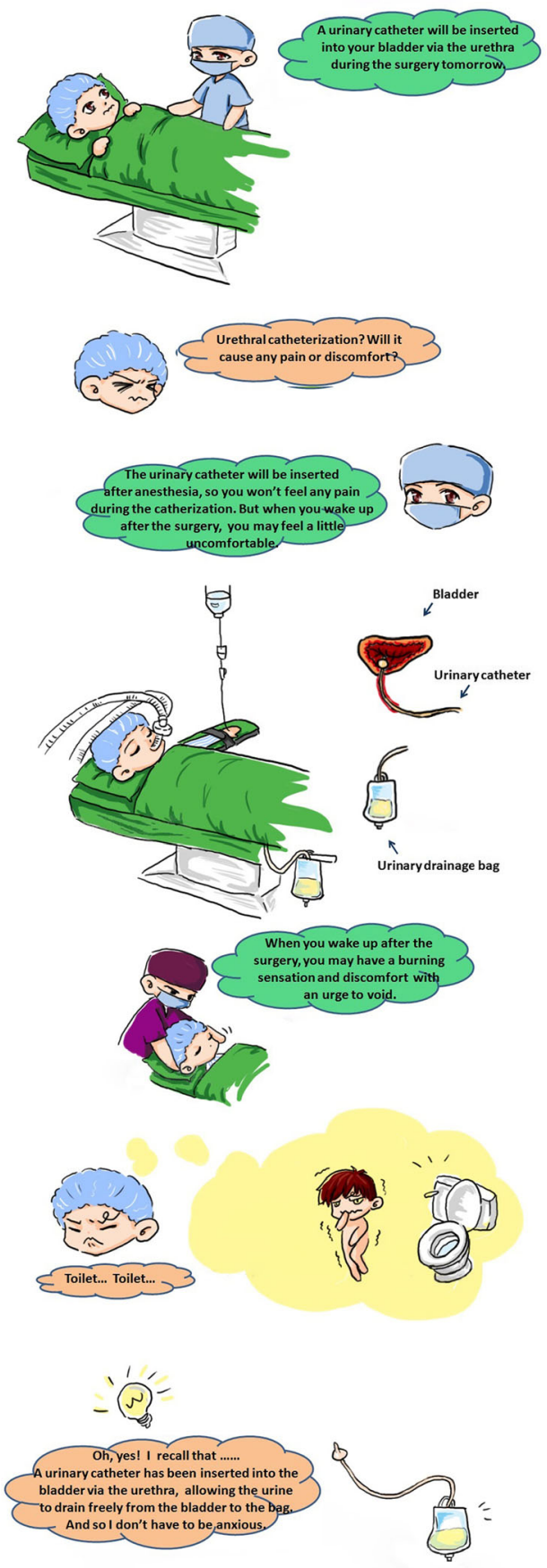

Dear Sir,

A urinary catheter will be inserted into your bladder via the urethra during the surgery tomorrow. The urinary catheter will be inserted after anesthesia, so you won't feel any pain during the

catherization. But when you wake up after the surgery, you may feel a little uncomfortable and a burning sensation with an urge to void.

So you don't have to be anxious since you have a urinary catherization.

Fig. 1 Instruction for uretheral catherization deep sedation, and toxicity of tetracaine. All of these outcomes were assessed at $0.5,1,2$, and $6 \mathrm{~h}$ after patients' extubation by a nurse blinded to the study design in PACU. The number of patients requiring sufentanil as rescue analgesics in PACU was also recorded.

CRBD was defined as a burning sensation at urethra with an urge to void, urinary frequency and painful discomfort in the supra-pubic region. The severity of CRBD was assessed according to the following scaling system: no CRBD; mild CRBD (complaint about CRBD on questioning only); moderate CRBD (complaint about CRBD without enquiring); and severe CRBD (complaint about CRBD without enquiring, with urinary urgency demonstrated by a spontaneous behavioral response such as flailing limb, verbal responses, or attempt to remove the catheter) [21]. Postoperative pain was assessed using a visual analog scale (VAS) score of 010 , where 0 represents no pain and 10 represents worst imaginable pain. Postoperative agitation and sedation levels were determined by Riker Sedation-Agitation Scale [22], where 5 to 7 represents agitation and 1 to 3 represents deep sedation (Additional file 1: Table S1).

\section{Sample size and statistical analysis}

In our pilot study, the incidence of CRBD was $55 \%$ in tetracain group. We assumed that preoperative education with image illustration would reduce the incidence of CRBD to $20 \%$. Based on a statistical power of $80 \%$ with a two-sided level of significance of $5 \%$, a sample size of 58 subjects were required (29 per group). A sample size of 64 subjects (32 per group) were planned to account for an expected dropout of $10 \%$.

All data analysis was performed using SPSS software (version 22.0, SPSS Inc., Chicago, Illinois). The normality of continuous data was tested by one-sample Kolmogorov-Smirnov test. We showed the mean (standard deviation) for a continuous data set if its normality assumption is met. Otherwise, we showed the median (interquartile range) for the data set. For continuous data sets that meet normality assumption, their population means were compared by independent samples Student's test. The population proportions of categorical data sets were compared using chi-square test or Fisher's exact test or Rank sum test. $P$-value $<0.05$ was considered significant.

\section{Results}

Among the 64 patients who were eligible for the study, 4 patients were excluded for that they refused to participate in the study (Fig. 2). Of the remaining 60 patients, 30 were randomized to tetracaine group and 30 


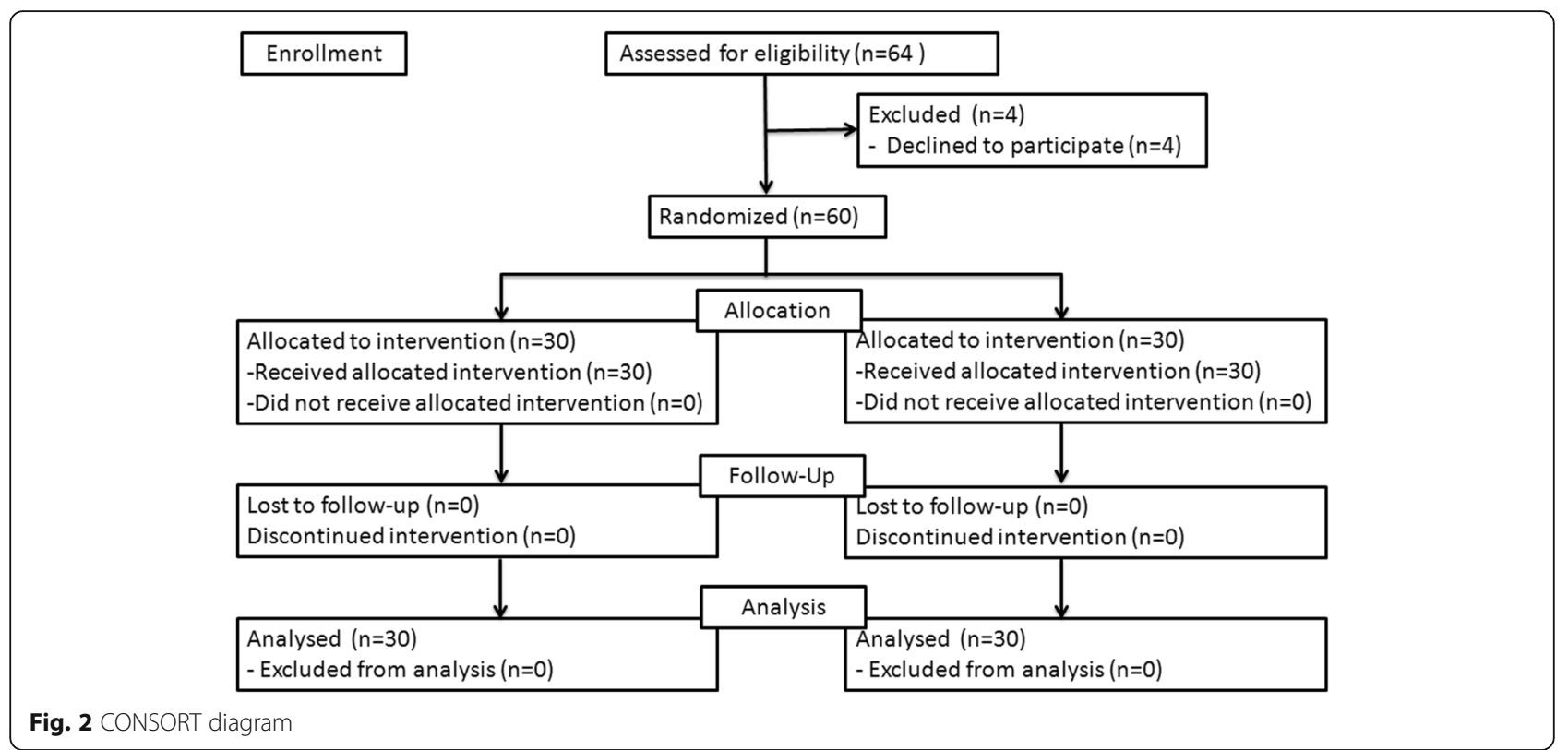

were randomized to image group (Fig. 2). And the data of sixty remaining patients were analysed.

Patients' baseline characteristics, surgical duration and the doses of intraoperative analgesics were similar between two groups (Table 1).

Patients in image group reported remarkably less CRBD than those in tetracaine group at $0.5 \mathrm{~h}(20 \%$ v.s.60\%, $P=0.002)$, 1 h (20\% v.s.73.3\%, $P=0.000), 2$ h $(6.7 \%$ v.s. $53.3 \%, P=0.000)$, and 6 h $(6.7 \%$ v.s. $53.3 \%, P=0.000)$ after extubation, respectively (Table 2 ). Moreover, the severity of CRBD observed were significantly different between two groups. Although none of the patients in either group reported severe CRBD, the incidence of moderate CRBD was remarkably lower in image group, with only $6.7 \%(2 / 30)$ at $1 \mathrm{~h}$ and thereafter none occurred in image group, whereas compared to $6.7 \%(0.5 \mathrm{~h})$, and increasing to $20 \%$ at $1 \mathrm{~h}, 2 \mathrm{~h}$ and $6 \mathrm{~h}$ in tetracaine group, respectively (Table 3 ), These data suggest that image illustration enhanced the effect of tetracaine in decreasing both the incidence and severity of CRBD.

Unexpectedly, there was no significant difference in incidence of postoperative pain (assessed by VAS scores) over time between two groups. However, stratified analysis showed that the occurrence of moderate to severe pain (VAS score $\geq 4$ ) were lower in image group than that of tetracaine group $(13.3 \%$ v.s. $40 \%$ at $1 \mathrm{~h}, P=0.039 ; 33.3 \%$ v.s. $60 \%$ at $2 \mathrm{~h}, P=0.038 ; 33.3 \%$ v.s. $60 \%$ at $6 \mathrm{~h}, P=0.038$, respectively) (Table 4$)$. In line with these findings, rescue analgesics (sufentanil was given if VAS $\geq 4$ ) were required more often in the tetracaine group than in the image group $(40 \%$ v.s. $13.3 \%$ at $1 \mathrm{~h}, P=0.039 ; 60 \%$ v.s.
$33.3 \%$ at $2 \mathrm{~h}, P=0.038 ; 60 \%$ v.s. $33.3 \%$ at $6 \mathrm{~h}, P=0.038$, respectively). However, the average dose of sufentanil in each patient receiving rescue sufentanil showed no difference $(0.49 \pm 0.27$ v.s. $0.41 \pm 0.26 \mu \mathrm{g} / \mathrm{kg}, \quad P=0.352)$ (Additional file 2: Table S2, Additional file 3: Table S3).

Interestingly, patients in image group did not have agitation (defined as SAS score 5 to7) after extubation, whereas the incidences of agitation in tetracaine group were $6.7 \%$ at $1 \mathrm{~h}$, which increased to $16.7 \%$ at $2 \mathrm{~h}$ and $13.3 \%$ at $6 \mathrm{~h}$, respectively (Table 5 ). The overall status of sedation level for all the patients showed no difference between 2 groups (Additional file 4: Table S4).

Table 1 Baseline characteristics of patients. Values are given as mean \pm SD or number of patients (\%)

\begin{tabular}{llll}
\hline & $\begin{array}{l}\text { Tetracaine group } \\
(n=30)\end{array}$ & $\begin{array}{l}\text { Image group } \\
(\mathrm{n}=30)\end{array}$ & $P$ value \\
\hline Age(yr) & $58.14 \pm 10.08$ & $51.27 \pm 13.58$ & 0.136 \\
Weight(Kg) & $59.13 \pm 9.63$ & $62.13 \pm 8.78$ & 0.380 \\
Height(cm) & $166.38 \pm 5.04$ & $167.92 \pm 6.55$ & 0.509 \\
Education level & & & 0.177 \\
$\quad$ Illiteracy & $2(6.7 \%)$ & $0(0 \%)$ & \\
$\quad$ Primary school & $6(20.0 \%)$ & $12(40.0 \%)$ & \\
$\quad$ Middle school & $12(40.0 \%)$ & $14(6.7 \%)$ & \\
$\quad$ High school & $4(13.3 \%)$ & $0(0 \%)$ & \\
$\quad$ College and above & $6(20.0 \%)$ & $4(13.3 \%)$ & \\
Duration of operation(h) & $3.13 \pm 1.13$ & $2.71 \pm 0.82$ & 0.334 \\
Intraoperative sufentanyl(ug/ & $0.43 \pm 0.30$ & $0.41 \pm 0.26$ & 0.842 \\
kg) & & & \\
\hline
\end{tabular}


Table 2 Incidence of catheter-related bladder discomfort. Values are given as number of patients (\%)

\begin{tabular}{llll}
\hline & $\begin{array}{l}\text { Tetracaine } \\
\text { group }(\mathrm{n}=30)\end{array}$ & $\begin{array}{l}\text { Image group } \\
(\mathrm{n}=30)\end{array}$ & P value \\
\hline $0.5 \mathrm{~h}$ & $18(60.0 \%)$ & $6(20.0 \%)$ & 0.002 \\
$1 \mathrm{~h}$ & $22(73.3 \%)$ & $6(20.0 \%)$ & 0.000 \\
$2 \mathrm{~h}$ & $16(53.3 \%)$ & $2(6.7 \%)$ & 0.000 \\
$6 \mathrm{~h}$ & $16(53.3 \%)$ & $2(6.7 \%)$ & 0.000 \\
\hline
\end{tabular}

Furthermore, no patients suffered from toxicity of local anaesthetics and other adverse events, including respiratory depression, and deep sedation in both groups.

\section{Discussion}

The present study demonstrates that preoperative education on uretheral catheterization and CRBD via verbal instruction in conjunction with image illustrations could enhance the effect of tetracaine mucilage in reducing both the incidence and severity of CRBD and alleviating emergence agitation.

CRBD is a common complication after uretheral catheterization in surgical male patients [6], with an incidence ranging from 47 to $90 \%[3,23]$. It is frequently associated with emergence agitation [3, 4], exacerbated postoperative pain, and other postoperative complications [3, 5]. Lubricants containing local anesthetic such as lidocaine or tetracaine, instilled into the urethra or applied to the catheter, are commonly used in urethral catheterization to minimize urethral trauma and decrease the incidence of postoperative CRBD [1] to certain extent. However, effective prevention and treatment for CRBD without adverse effects, has not been established yet.

On the other hand, there is growing evidence indicating that preoperative education programs could be implemented to alleviate anxiety, postoperative pain and discomfort [14]. These programs, with content varies greatly, may include verbal instruction, one or combination of an operating area visit, and peer modelling preparation using videos, instruments or images [18]. In our study, in addition to applying lubricants containing tetracaine during urethral catheterization, we used verbal instruction combining with image illustration during preoperative visit,explaining the whole process from urethral catheterization and the symptoms of CRBD, which will enable the patients to understand and remember the related information. We found that preoperative education via verbal instruction in conjunction with image illustrations enhanced the effect of tetracaine mucilage by reducing at least a half of the incidence of CRBD, and further decreases the severity of CRBD. These findings indicated that image illustration in combination with tetracain, as a simple and economic way, is effective in decreasing both the incidence and severity of CRBD.

Interestingly, patients in image group experienced less moderate and severe pain, unlike up to $40-60 \%$ in tetracaine group after $1 \mathrm{~h}$. Moreover, fewer rescue analgesics were required in the image groups than that in the tetracaine group. This emphasizes the need for effective preoperative education on CRBD via such simple and economic way to be included in the preoperative preparation.

Several limitations of the current study should also be considered. Firstly, only male patients who were to undergo elective colonal and rectal surgery, were included. We did not include female patients and did not observe other procedures, such as urological surgery, because these surgeries may affect the occurrence of postoperative CRBD. Therefore, limitations exist in the application of image preoperative education to patients who undergo other operations requiring urethral catheterization. Secondly, urethral catheterization was performed using unified 16-Fr Foley catheters, and we did not compare Foley catheters with other size catheters. A large diameter Foley catheter is a known risk factor for CRBD. Thirdly, as most studies investigating CRBD suggested, their observation period of CRBD is usually within $6 \mathrm{~h}$ after operation [1, 2, 24, 25], partly because the incidence of CRBD reached its peak mainly in $6 \mathrm{~h}$ after surgery, and patients in this study usually stayed in PACU for $6 \mathrm{~h}$, therefore, we did not evaluate whether image illustrations are beneficial for longer duration. Lastly, we did not measure the uroflowmetry, the residual

Table 3 Severity of catheter-related bladder discomfort. Values are given as number of patients (\%)

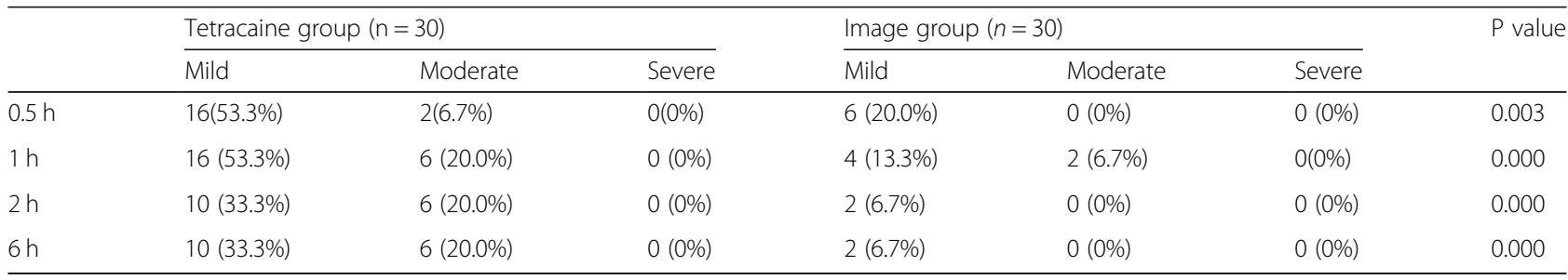


Table 4 Incidence and severity of postoperative pain

\begin{tabular}{|c|c|c|c|c|c|}
\hline & \multicolumn{2}{|c|}{ Tetracaine group $(n=30)$} & \multicolumn{2}{|c|}{ Image group $(n=30)$} & \multirow{2}{*}{$\begin{array}{l}\text { P value } \\
\text { \& Severe }\end{array}$} \\
\hline & Mild & Moderate \& Severe & Mild & Moderate \& & \\
\hline $0.5 \mathrm{~h}$ & $26(86.7 \%)$ & $4(13.3 \%)$ & $28(93.3 \%)$ & $2(6.7 \%)$ & 0.671 \\
\hline $1 \mathrm{~h}$ & $18(60.0 \%)$ & $12(40.0 \%)$ & $26(86.7 \%)$ & $4(13.3 \%)$ & 0.039 \\
\hline $2 \mathrm{~h}$ & $12(40.0 \%)$ & $18(60.0 \%)$ & $20(66.7 \%)$ & $10(33.3 \%)$ & 0.038 \\
\hline $6 \mathrm{~h}$ & $12(40.0 \%)$ & $18(60.0 \%)$ & 20 (66.7\%) & 10 (33.3\%) & 0.038 \\
\hline
\end{tabular}

urine and the size of prostate which might be a confounding factor to affect the result.

\section{Conclusions}

In conclusion, preoperative education on uretheral catheterization via verbal instruction in conjunction with image illustrations could enhance the effect of tetracaine mucilage in reducing both the incidence and severity of CRBD. Moreover, the preoperative education reduced the incidence of postoperative from moderate to severe pain along with decreasing the number of patients requiring sufentanil, and alleviating emergence agitation. We therefore suggest that preoperative education via image illustration on uretheral catheterization should be included in the preoperative preparation for surgical patient requiring catheterization of the urinary bladder. Image illustration in combination with tetracaine is a simple, economic, safe and effective method to decrease both the incidence and severity of CRBD.

\section{Additional files}

Additional file 1: Table S1. Riker Sedation-Agitation Scale. (DOCX 64 kb) Additional file 2: Table S2. The number of patients received rescue sufentanil in each group. (DOCX $63 \mathrm{~kb}$ )

Additional file 3: Table S3. The average dose of sufentanil in each patient received rescue analgesics in the PACU. (DOCX $61 \mathrm{~kb}$ )

Additional file 4: Table S4. The status of sedation level. (DOCX 62 kb)

\section{Abbreviations}

CRBD: Catheter-related bladder discomfort; PACU: Postanesthesia care unit; SAS: Sedation-Agitation Scale; VAS: Visual Analogue Scale/Score

\section{Acknowledgements}

The authors thank all staff in the department of anaesthesiology of West China Hospital, Sichuan University, Chengdu, China for their help in the study.

Table $\mathbf{5}$ Incidences of postoperative agitation

\begin{tabular}{llll}
\hline & $\begin{array}{l}\text { Tetracaine group } \\
(\mathrm{n}=30)\end{array}$ & $\begin{array}{l}\text { Image group } \\
(\mathrm{n}=30)\end{array}$ & P value \\
\hline $0.5 \mathrm{~h}$ & $0(0 \%)$ & $0(0 \%)$ & - \\
$1 \mathrm{~h}$ & $2(6.7 \%)$ & $0(0 \%)$ & 0.492 \\
$2 \mathrm{~h}$ & $5(16.7 \%)$ & $0(0 \%)$ & 0.052 \\
$6 \mathrm{~h}$ & $4(13.3 \%)$ & $0(0 \%)$ & 0.112 \\
\hline
\end{tabular}

\section{Funding}

The design of the study, writing the manuscript and publication of the manuscript were supported by the National Natural Science Foundation of China (81600006). The design of the study and collection of the data were supported by the National Natural Science Foundation of China (81671887) The analysis and interpretation of data were supported by by Training Plan of Excellent Young Medical Talents in Shanghai (2017YQ015). The analysis and interpretation of data were supported by 1.3 .5 project for disciplines of excellence, West China Hospital, Sichuan University.

\section{Availability of data and materials}

All data generated or analysed during this study are included in this published article and are available from the corresponding author on reasonable request.

\section{Authors' contributions}

L. Z. (Li Zhou) Contribution: Design the study, analyze and interpret the data and revise the manuscript. L. Z. (Le Zhou) Contribution: Design the study and write the manuscript. LL. T. Contribution: Conduct the study and analyze the data. DJ.Z. Contribution: Conduct the study and analyze the data. ZW.C. Contribution: Conduct the study and write the manuscript. C. Z. Contribution: Conduct the study and analyze the data. T. Z. Contribution: Conduct the study, analyze and interpret the data. XZ. Z. Contribution: Conduct the study and do the critical manuscript review. XJ. J. Conduct the study and do the critical manuscript review. CL. J. Contribution: Design the study, interpret the data, and revise the manuscript. LL. B. Contribution: Analyze and interpret the data, and revise the manuscript. All authors read and approved the final manuscript.

\section{Ethics approval and consent to participate}

This study was approved by Ethical Committee of West China Hospital, Chengdu, China (Ethical Committee $N^{\circ}$ 2014-159). After a detailed explanation written informed consent was obtained from 60 patients scheduled for elective colonal and rectal surgery.

\section{Consent for publication}

Not applicable.

\section{Competing interests}

The authors declare that they have no competing interests.

\section{Publisher's Note}

Springer Nature remains neutral with regard to jurisdictional claims in published maps and institutional affiliations.

\section{Author details}

${ }^{1}$ Department of Anaesthesiology and Translational Neuroscience Center, West China Hospital, Sichuan University, Chengdu 610041, Sichuan, China. ${ }^{2}$ Department of Anaesthesiology, Sichuan Jinxin Women and Children's Hospital, Chengdu 610011, Sichuan, China. 'Faculty of Anaesthesiology, Changhai Hospital, Naval Medical University, Shanghai 200433, China.

Received: 28 August 2018 Accepted: 27 November 2018

Published online: 22 December 2018

\section{References}

1. Ryu JH, Hwang JW, Lee JW, Seo JH, Park HP, Oh AY, Jeon YT, Do SH. Efficacy of butylscopolamine for the treatment of catheter-related bladder discomfort: a prospective, randomized, placebo-controlled, double-blind study. Br J Anaesth. 2013;111(6):932-7.

2. Agarwal A, Yadav G, Gupta D, Singh PK, Singh U. Evaluation of intra-operative tramadol for prevention of catheter-related bladder discomfort: a prospective, randomized, double-blind study. Br J Anaesth. 2008;101(4):506-10.

3. Bai Y, Wang X, Li X, Pu C, Yuan H, Tang Y, Li J, Wei Q, Han P. Management of Catheter-Related Bladder Discomfort in patients who underwent elective surgery. J Endourol. 2015;29(6):640-9.

4. Wilson M. Causes and management of indwelling urinary catheter-related pain. Br J Nurs. 2008;17(4):232-9.

5. Lepouse C, Lautner CA, Liu L, Gomis P, Leon A. Emergence delirium in adults in the post-anaesthesia care unit. Br J Anaesth. 2006;96(6):747-53.

6. Srivastava VK, Agrawal S, Kadiyala VN, Ahmed M, Sharma S, Kumar R. The efficacy of pregabalin for prevention of catheter-related bladder discomfort: 
a prospective, randomized, placebo-controlled double-blind study. J Anesth. 2015;29(2):212-6.

7. Agarwal A, Dhiraaj S, Singhal V, Kapoor R, Tandon M. Comparison of efficacy of oxybutynin and tolterodine for prevention of catheter related bladder discomfort: a prospective, randomized, placebo-controlled, double-blind study. Br J Anaesth. 2006;96(3):377-80.

8. Tauzin-Fin P, Sesay M, Svartz L, Krol-Houdek MC, Maurette P. Sublingual oxybutynin reduces postoperative pain related to indwelling bladder catheter after radical retropubic prostatectomy. Br J Anaesth. 2007;99(4):572-5.

9. Kim HC, Lee YH, Jeon YT, Hwang JW, Lim YJ, Park JE, Park HP. The effect of intraoperative dexmedetomidine on postoperative catheter-related bladder discomfort in patients undergoing transurethral bladder tumour resection: a double-blind randomised study. Eur J Anaesthesiol. 2015;32(9):596-601.

10. Maghsoudi R, Farhadi-Niaki S, Etemadian M, Kashi AH, Shadpour P, Shirani A, Samadinezhad-Khoshbaf-Sorkhabi R, Tabatabaei M. Comparing the efficacy of Tolterodine and gabapentin versus placebo in catheter related bladder discomfort after percutaneous Nephrolithotomy: a randomized clinical trial. J Endourol. 2018;32(2):168-74.

11. Mu L, Geng LC, Xu H, Luo M, Geng JM, Li L. Lidocaine-prilocaine cream reduces catheter-related bladder discomfort in male patients during the general anesthesia recovery period: a prospective, randomized, case-control STROBE study. Medicine. 2017;96(14):e6494.

12. Yang $B$, Chen $Q$, Jiang JH, Liu HL. The comparative study of lidocaine and tetracaine urethral surface anesthesia in catheter related bladder discomfort of male patients after thoracoscopy surgery. J Pract Med. 2017;33(12):2019-202213.

13. Lin $\mathrm{YH}$, Chen GQ. Analysis about tetracaine hydrochloride mucilage on restless of male patients with urethral catheterization after general anesthesia. Xinjiang Med J. 2017;7:727-9.

14. Katz J, Poleshuck EL, Andrus CH, Hogan LA, Jung BF, Kulick DI, Dworkin RH. Risk factors for acute pain and its persistence following breast cancer surgery. Pain. 2005;119(1-3):16-25.

15. Ronco M, lona L, Fabbro C, Bulfone G, Palese A. Patient education outcomes in surgery: a systematic review from 2004 to 2010. Int J Evid Based Healthc. 2012;10(4):309-23.

16. Sjoling M, Nordahl G, Olofsson N, Asplund K. The impact of preoperative information on state anxiety, postoperative pain and satisfaction with pain management. Patient Educ Couns. 2003;51(2):169-76.

17. Oshodi TO. The impact of preoperative education on postoperative pain. Part 2. Br J Nurs. 2007;16(13):790-7.

18. Fincher W, Shaw J, Ramelet AS. The effectiveness of a standardised preoperative preparation in reducing child and parent anxiety: a singleblind randomised controlled trial. J Clin Nurs. 2012;21(7-8):946-55.

19. Ramesh C, Nayak BS, Pai VB, Patil NT, George A, George LS, Devi ES. Effect of preoperative education on postoperative outcomes among patients undergoing cardiac surgery: a systematic review and meta-analysis. J Perianesth Nurs : official journal of the American Society of PeriAnesthesia Nurses. 2017:32(6):518-29 e512

20. Choi J. Literature review: using pictographs in discharge instructions for older adults with low-literacy skills. J Clin Nurs. 2011;20(21-22):2984-96.

21. Li JY, Yi ML, Liao R. Dorsal penile nerve block with Ropivacaine-reduced postoperative catheter-related bladder discomfort in male patients after emergence of general anesthesia: a prospective, randomized, controlled study. Medicine (Baltimore). 2016;95(15):e3409.

22. Riker RR, Picard JT, Fraser GL. Prospective evaluation of the sedation-agitation scale for adult critically ill patients. Crit Care Med. 1999;27(7):1325-9.

23. Hu B, Li C, Pan M, Zhong M, Cao Y, Zhang N, Yuan H, Duan H. Strategies for the prevention of catheter-related bladder discomfort: a PRISMA-compliant systematic review and meta-analysis of randomized controlled trials. Medicine. 2016;95(37):e4859.

24. Agarwal A, Dhiraaj S, Pawar S, Kapoor R, Gupta D, Singh PK. An evaluation of the efficacy of gabapentin for prevention of catheter-related bladder discomfort: a prospective, randomized, placebo-controlled, double-blind study. Anesth Analg. 2007;105(5):1454-7 table of contents.

25. Agarwal A, Raza M, Singhal V, Dhiraaj S, Kapoor R, Srivastava A, Gupta D, Singh PK, Pandey CK, Singh U. The efficacy of tolterodine for prevention of catheterrelated bladder discomfort: a prospective, randomized, placebo-controlled, double-blind study. Anesth Analg. 2005;101 (4):1065-7 table of contents.

Ready to submit your research? Choose BMC and benefit from:

- fast, convenient online submission

- thorough peer review by experienced researchers in your field

- rapid publication on acceptance

- support for research data, including large and complex data types

- gold Open Access which fosters wider collaboration and increased citations

- maximum visibility for your research: over $100 \mathrm{M}$ website views per year

At BMC, research is always in progress.

Learn more biomedcentral.com/submissions 